\title{
ESCRIBIR, LEER Y CONVERSAR ENTRE DOCENTES EN TORNO DE RELATOS DE EXPERIENCIA
}

\author{
DANIEL HUGO SUÁREZ \\ Universidad de Buenos Aires \\ Facultad de Filosofía y Letras
}

RESUMEN

En este texto pretendo poner en debate las potencialidades metodológicas y políticas de la documentación narrativa de experiencias como una modalidad de trabajo pedagógico entre docentes, que promueve la participación de los educadores en procesos de indagación, desarrollo profesional y acción en el campo educativo, y que tiende a democratizar las relaciones de saber y de poder que lo atraviesan y constituyen. Para eso, en un primer apartado, presento los criterios teóricos y metodológicos que informan a la documentación narrativa como una modalidad particular de investigación-formación-acción que se inscribe en el campo pedagógico y que dialogan con diversas tradiciones de investigación social y educativa. En un segundo apartado, enumero y describo los diferentes, sucesivos y recursivos "momentos" del trayecto de investigación-formación-acción docente centrado en la elaboración participativa de relatos de experiencia pedagógica, con el fin de mostrar cómo aquellos recaudos metodológicos se actualizan en el dispositivo de trabajo, movilizan activas prácticas de escritura, lectura, comentario y conversación entre pares y promueven nuevas formas de conciencia profesional.

Palabras clave: Documentación narrativa. Investigación-formaciónacción. Relatos de experiencia. Campo pedagógico. Participación

\section{ABSTRACT WRITING, READING AND CONVERSATION AMONG TEACHERS ABOUT NARRATIVES OF EXPERIENCE}

This text intends to put in discussion the methodological and political potentialities of the narrative documentation of experiences as a modality of pedagogical work among teachers, which promotes the participation of the educators in their inquiry processes, professional development and action in the educational field, and that tends to democratize the relation of knowledge and power in which it goes through. For that, in the first moment I present the theoretical 
and the methodological background that show the narrative documentation as a particular modality of an action research enrolled in the pedagogical field which dialogues with different traditions of social and educational researches. In the second moment, I list and describe the different, successive and recursive "moments" of the action research path of teachers focused on the participatory development of the narratives of pedagogical experience, in order to show how those methodological requirements are updated in the work device, mobilize active practices of writing, reading, commenting and conversation in pairs and promote new ways of professional conscience.

Keywords: Narrative documentation. Action research. Narratives of experience. Pedagogical field. Participation.

Neste texto, pretendo colocar em debate as potencialidades metodológicas e políticas da documentação narrativa de experiência, como uma modalidade de trabalho pedagógico entre os docentes, que promove a participação dos educadores, em processos de indagação, desenvolvimento profissional e ação, no campo educativo, e que tende a democratizar as relações de saber e de poder que atravessa e constitui. Para isso, em um primeiro instante, apresento os critérios teóricos e metodológicos, que informam a documentação narrativa, como uma modalidade particular de investigação-formação-ação inscrita no campo pedagógico, e que dialogam com diversas tradições de investigação social e educativa. No segundo momento, enumero e descrevo os diferentes, sucessivos e recursivos "momentos" do trajeto da investigação-formação-ação docente centrado na elaboração participativa de relatos de experiência pedagógica, com o objetivo de mostrar como aqueles requisitos metodológicos atualizam-se no dispositivo de trabalho, mobilizam práticas ativas de escrita, leitura, comentário e conversação, entre pares, e promovem novas formas de consciência profissional.

Palavras-chave: Documentação narrativa. Investigação-formação-ação. Relatos de experiencia. Campo pedagógico. Participação. 
La experiencia también puede ser asequible a los demás mediante el relato post facto, un proceso de elaboración secundaria en el sentido freudiano que la convierte en una narrativa dotada de significación. Cuando esas reconstrucciones y relatos de la experiencia se comparten, suelen transformarse en la materia de identidades grupales (JAY, 2009, p. 20)

\section{Documentación narrativa de experiencias pedagógicas, participación docente y campo pedagógico}

En este texto pretendo poner en debate las potencialidades metodológicas de la documentación narrativa de experiencias como una modalidad de trabajo pedagógico entre docentes, que promueve la participación de los educadores en procesos de indagación, desarrollo profesional y acción en el campo educativo, y que tiende a tornar más horizontales las relaciones de saber y de poder que lo atraviesan y constituyen (SUÁREZ, 2015a). Esta estrategia de investigación-formación-acción docente organiza y regula una serie de prácticas narrativas y autobiográficas para que los participantes tengan la oportunidad de relatar historias acerca de su práctica docente, y para que esas formas de interpretación del mundo escolar sean puestas en escritura, indagación, deliberación pública y cambio. De esta forma, la documentación narrativa se afilia a una tradición y un movimiento pedagógico que se orientan hacia la transformación democrática de la escuela, y que se inclina a generar y sostener espacios de trabajo coparticipado y en red en los campos de la investigación educativa y la formación docente (SUÁREZ, 2015b; SUÁREZ y ARGNANI, 2011). En particular, le interesa activar la memoria pedagógica de la escuela y "profundizar narrativamente" el discurso público acerca de la educación mediante la producción, publicación y circulación de relatos de experiencias pedagógicas escritos por docentes.
Mi intención es mostrar parte de lo que hemos aprendido en más de quince años de "experimentación metodológica y política" (MARTÍNEZ BOOM y PEÑA RODRÍGUEZ, 2009) mediante una sucesión de proyectos y experiencias de documentación narrativa junto con diversos actores del campo pedagógico. Como grupo de investigación y de extensión universitaria de la Facultad de Filosofía y Letras de la Universidad de Buenos Aires, hemos trabajado junto a gobiernos educativos, administraciones escolares y ministerios de educación, trabajo y desarrollo social, a nivel nacional, provincial y municipal; sindicatos y organizaciones docentes; instituciones superiores de formación docente y otras universidades nacionales y latinoamericanas; redes pedagógicas y colectivos docentes internacionales, nacionales y regionales; movimientos pedagógicos y organizaciones sociales de distintos países de América Latina. Y lo hicimos a distintas escalas territoriales, con diferente cantidad de participantes, en geografias diversas, en muchos niveles del sistema educacional y en otras organizaciones del campo pedagógico, e involucrando la participación de muchos y diferentes actores de ese campo: docentes de todos los niveles y modalidades del sistema educativo; directores y supervisores escolares; equipos técnicos y profesionales; directores de nivel educativo o de diversas instancias de ministerios y secretarias de educación; sindicalistas docentes y militantes sociales; educadores populares y alfabetizadores de organizaciones sociales y comunitarias (SUÁREZ, 2016).

A través de esa experiencia intensa, productiva y colectiva, la documentación narrativa ha ganado legitimidad como una modalidad de investigación-formación-acción docente que se inscribe, desarrolla y valida en el campo pedagógico, y que se orienta a visibilizar, poner en tensión y profundizar los 
modos de decir y hacer en el mundo escolar. Forma parte de la expansión del "espacio biográfico" hacia el territorio de la educación y la pedagogía (SUÁREZ, 2014). Su propósito de conocimiento es re-elaborar de manera participativa saberes pedagógicos públicos a partir de los saberes de experiencia que los docentes construyen cuando ejercen su oficio de educar y cuando habitan, hacen y nombran sus mundos (CONTRERAS Y PEREZ DE LARA, 2010; ALLIAUD y SUÁREZ, 2011). Sus objetivos de formación se dirigen a la organización de "comunidades de atención mutua" (CONNELY Y CLANDININ, 1995) que propicien relaciones de horizontalidad entre los participantes y la transmisión recíproca de los "saberes de oficio" mediante la escritura, la lectura, el comentario y la conversación sobre relatos de experiencia.

Para alcanzar estas metas, el itinerario de trabajo de esta forma particular de documentación pedagógica dispone y moviliza un conjunto de recaudos metodológicos para que los participantes indaguen momentos significativos de sus trayectorias de formación y vidas profesionales; pongan en reflexión, tensión y debate las comprensiones pedagógicas que construyeron en esos recorridos laborales y profesionales; y puedan reconstruirlas, problematizarlas y transformarlas mediante la documentación narrativa de las experiencias vividas en las escuelas y reflexionadas en comunidades de prácticas (SUÁREZ, 2007). De esa forma, incorporados a colectivos de investigación-formación, que adoptan la modalidad de "talleres", los participantes se tornan "docentes narradores/as" de sus propias experiencias pedagógicas y se comprometen en procesos cooperativos de escritura y re-escritura, de lectura entre pares y de conversación informada en torno de sucesivas versiones de relatos. A través de estos momentos claves del dispositivo metodológico, y con la coordina- ción de otros docentes narradores más experimentados o investigadores universitarios, los participantes llevan adelante la investigación narrativa y la documentación pedagógica de sus propios mundos escolares y se comprometen en procesos de auto y co-formación entre pares (SUÁREZ, 2012).

En el transcurso del trabajo colectivo y cooperativo, los docentes se forman al mismo tiempo que narran, investigan y tematizan las maneras en que otorgan sentido y dotan de significaciones a sus mundos profesionales y laborales. Cuando los docentes narradores relatan y re-escriben los sucesos y eventos de las escuelas en los que participaron, hacen explícito el saber de la experiencia y lo reelaboran buscándoles palabras y tramas narrativas que den cuenta de su vitalidad. De esta forma, tornan su conciencia práctica en discursiva -es decir, se constituyen en sujetos de enunciación, recepción, interlocución e interpretación-, y sus discursos y saberes se vuelven plausibles de críticas, evaluaciones, comentarios y nuevas lecturas e interpretaciones: las propias, pero también las de otros docentes, otros investigadores y otros actores del campo pedagógico. Al carácter formativo propio de la escritura y la lectura solitarias del propio relato, se suma la potencia reflexiva de la lectura y los comentarios de los otros docentes narradores y de los investigadores. Finalmente, cuando ese colectivo de docentes dispone públicamente los relatos de experiencia pedagógica elaborados en su marco y los hacen circular en diversos circuitos de recepción especializados, los docentes narradores se tornan autores de textos y documentos pedagógicos e intervienen a través de ellos en el debate educativo del campo pedagógico. Por eso, desde el punto de vista de esta estrategia de investigación-formación-acción, documentar la propia experiencia no es solamente escribir relatos, y tampoco escribirlos solos. 


\section{Investigación-formación-acción pedagógica en diálogo con la investigación social cualitativa}

Los criterios teóricos y metodológicos que informan a la documentación narrativa de experiencias son propios, específicos al campo pedagógico y a la "investigación de la experiencia educativa" (CONTRERAS Y PÉREZ DE LARA, 2010): pretenden organizar el desarrollo de la investigación-formación-acción de los docentes con arreglo a las reglas de juego que rigen en el territorio de la práctica situada y de la indagación pedagógica. Pero no obstante esta especificidad, los recaudos metodológicos para el trabajo pedagógico entre pares se inspiran y dialogan con algunas tradiciones de investigación social cualitativa que favorecen su despliegue. A través de estos criterios, esta estrategia también participa de los debates del campo de las ciencias de la educación y la investigación educativa. Estas tradiciones de investigación en conversación con la documentación narrativa son la etnografía de la educación, la investigación (auto)biográfico y narrativa, la investigación-acción-participativa, la investigación docente participativa, los talleres de educadores $y$, fundamentalmente, los talleres de investigación de la práctica docente.

Sin embargo, lo que venimos haciendo entre docentes narradores e investigadores universitarios en torno de la reconstrucción narrativa de la práctica dificilmente pueda encuadrarse en sentido estricto en alguna de estas formas de investigar la educación. Toma aportes de ellas, pero los dispone y reelabora en función sus estrategias de trabajo, que son, como enfaticé, fundamentalmente pedagógicas. De la etnografía de la educación (ROCKWELL, 2009) hace suyos el imperativo de "documentar los aspectos no documentados de la vida cotidiana de las escuelas y la necesidad de dotar de "densidad"a sus producciones textuales. Sin embargo, los relatos de experiencia pedagógica de los docentes no se construyen como reportes etnográficos, ni como "descripciones densas". Tienen otras reglas de composición y persiguen fines diferentes a los antropológicos. Y más allá de que pueden resultar de interés para los antropólogos de la educación como "fuentes primarias, sus destinatarios directos y sus lectores imaginados son otros docentes y otros actores del campo pedagógico.

De la investigación (auto)biográfica y narrativa (BOLÍVAR, 2002), considera sus contribuciones metodológicas relacionadas con la reconstrucción autobiográfica de las trayectorias profesionales de los docentes (BULLOUGH, 2000) y con las potencialidades de la narrativa para dar cuenta, documentar y problematizar de la propia experiencia vivida. No obstante, los relatos de experiencia que elaboran y re-elaboran los docentes narradores en el taller de documentación se configuran en torno de la experiencia escolar (o pedagógica) y no sobre la biografia profesional de los docentes. Contienen elementos autobiográficos pero no son, en sentido estricto, autobiografias o historias de vida. Los relatos hablan de la experiencia pedagógica en las que participaron los docentes narradores y del mundo escolar e histórico que ellos habitan y cuentan. Para eso sin dudas incorporan elementos autobiográficos, pero lo hacen en la medida que contribuyen a configurar la "intriga pedagógica" del relato.

De la investigación-acción-participativa y de la investigación-acción docente (ANDERSON y KERR, 2007), recupera la importancia epistemológica, metodológica, política y ética otorgada a los procesos participativos de producción de conocimientos y a la conversación horizontal entre los investigadores académicos y los sujetos participantes para acordar los términos de los procesos de producción conjunta. Asimismo, presta atención a sus criterios de validación como estrategia de pro- 
ducción de conocimientos. Y de los talleres de investigación cualitativa y participante de la práctica docente hereda muchas cosas, sobre todo la "metodología de taller", esto es, una particular forma de organización, disposición y gestión de los tiempos, espacios y recursos teóricos y metodológicos de la investigación social para la"realización de la participación en el marco de aproximaciones dialógicas de investigación" (BATALLÁN, 2007). Y también ha aprendido el convencimiento en las potencialidades de la empatía productiva en el trabajo colaborativo y participativo entre investigadores-coordinadores de taller y los docentes investigadores narrativos de la práctica.

Pero también se diferencia de esos talleres en una serie de cuestiones. Quizá la más importante sea que en la documentación narrativa no se pretende iniciar e incorporar a los docentes en prácticas de investigación social cualitativa de la práctica docente. Lo que se propone es convidar a los docentes a que narren sus historias pedagógicas, a que cuenten sus experiencias escolares, a que hagan lo que suelen hacer: contar relatos pedagógicos, pero dentro de ciertas reglas de juego y bajo determinadas condiciones organizacionales y metodológicas en cuya definición están también invitados a participar. De hecho, los docentes narradores se involucran cada vez más en la generación y el sostenimiento de las condiciones políticas, organizacionales, institucionales y pedagógicas que hacen posible y habilitan procesos de documentación narrativa. Esta es también otra diferencia.

\section{El trayecto de la documentación} narrativa: momentos de la investigación-formación-acción docente

Como anticipé, en el transcurso de los últimos quince años hemos realizado muchas expe- riencias de documentación narrativa en terreno, y cada una de ellas ha sido particular, única, realizada junto con diferentes actores del campo pedagógico, a diferentes escalas y con la participación de diferentes docentes narradores. Una de las potencialidades metodológicas de la documentación narrativa de experiencias pedagógicas es, justamente, la capacidad y plasticidad de su dispositivo de trabajo para adaptarse a contextos diversos y a las distintas circunstancias políticas, institucionales y pedagógicas que los caracterizan y sitúan.

Pero más allá de la forma particular que esta modalidad de indagación-formación-acción docente haya tomado en cada caso, es posible delimitar una serie sucesiva y recursiva de "momentos metodológicos" que permite una descripción más pormenorizada del trayecto de trabajo pedagógico que traza la documentación narrativa y una comprensión más profunda acerca de cómo los docentes narradores participan activamente en cada una de las instancias. Esos momentos sucesivos y recursivos son: a) la generación de condiciones políticas, institucionales y pedagógicas adecuadas para la investigación-formación-acción docente participativa; b) la identificación y la selección de experiencias a documentar; c) la escritura y re-escritura de distintas versiones del relato de experiencia; d) la lectura, los comentarios y la conversación en torno de las sucesivas versiones de los relatos, es decir, la "edición pedagógica"; e) la publicación de los relatos; y f) la circulación de los documentos narrativos en circuitos de recepción especializados. A continuación los describiré de manera sintética, así como presentaré algunos ejemplos que permitan tornar visible la participación de los docentes narradores y otros actores del campo pedagógico en cada momento del trayecto Por este camino espero poder mostrar cómo se involucran en proce- 
sos de reelaboración del saber construido en la experiencia pedagógica.

\section{Generación de condiciones políticas, institucionales y pedagógicas}

Esta estrategia de trabajo pedagógico entre pares supone una ruptura con las modalidades convencionales e instituidas de trabajo docente y un corte en el flujo rutinario de las actividades escolares. Implica inventar tiempos y espacios y disponer arreglos normativos y micropolíticos que garanticen oportunidades de investigación, formación y trabajo colaborativo entre docentes y entre éstos e investigadores académicos, que la mayoría de las veces no están dados y que cuesta conseguir. Por eso, generar y sostener condiciones políticas y habilitaciones institucionales para que los educadores puedan involucrarse activamente en procesos de documentación narrativa resulta una condición de posibilidad para el despliegue del dispositivo. La documentación narrativa de experiencias se inscribe y desarrolla en el campo pedagógico, y en éste no se dispone con facilidad de tiempos, espacios y recursos normativos y administrativos para la investigación pedagógica de los actores escolares y la formación entre pares.

De hecho, los proyectos efectivamente desplegados en territorio lograron llevarse a la práctica porque cada uno fue amparado en una serie de acuerdos de trabajo que sostuvieron la iniciativa hasta su consecución. Cuando esos arreglos políticos e institucionales no se logran, dificilmente pueda desarrollarse un proceso de documentación narrativa. Sirve para ilustrar esta exigencia las dificultades que encontraron muchos proyectos para implementarse o ganar continuidad. Por ejemplo, el proyecto de documentación narrativa de experiencias pedagógicas en el nivel inicial de- sarrollado en conjunto con la Dirección del nivel en tres regiones educativas la Provincia de Buenos Aires, solo pudo seguir profundizándose y ampliándose en una sola de las regiones educativas (La Matanza), en tanto que allí se lograron acuerdos con la Jefatura Regional de Educación y un grupo de supervisoras escolares comprometidas con la investigación-formación-acción docente. La consecuencia de esa negociación fue que la administración escolar regional incluyó a la documentación narrativa como una línea de trabajo posible de supervisores, directivos y docentes de todos los niveles escolares en el plan político educativo local. En las otras dos regiones educativas (Pilar y San Martín), en cambio, una vez concluido el proyecto provincial, se discontinuó el trabajo, entre otras cosas, porque las jefaturas regionales de educación no les dieron su apoyo, no se contó con habilitaciones institucionales para la participación de los docentes y tampoco hubo actores escolares que la demandarán.

Para lograr que las condiciones de producción de la documentación narrativa se sostengan, el dispositivo metodológico prevé desde el principio y a lo largo del proceso el trabajo en cooperación de investigadores, docentes y referentes institucionales y de administraciones educativas (autoridades y equipos técnicos de ministerios de educación, supervisores escolares, directores de escuelas). $Y$ eso requiere la definición de momentos específicos de intercambio para alcanzar acuerdos y establecer reglas de juego que hagan posible el trayecto de investigación-formación-acción participativo. Esta instancia del dispositivo incluye la "invitación"de los docentes a integrarse al trabajo y requiere la explicitación clara de los compromisos a asumir y de los recaudos, garantías y certificaciones dispuestos institucionalmente para que la participación sea posible. La incorporación al colectivo de docentes narradores 
y al proceso de documentación narrativa es necesariamente voluntaria, a contramano de las habituales "convocatorias" oficiales obligatorias, y su participación requiere ser también negociada a lo largo de todo el trayecto.

\section{Identificación y selección de la experiencia a documentar}

La identificación y la selección de las experiencias a documentar pueden considerarse el momento inicial del trayecto de documentación en sentido estricto, aunque las operaciones intelectuales que están involucradas con su desenvolvimiento se encuentren también en otros momentos del trabajo. Las tareas destinadas a definir qué experiencias se van a documentar es estratégica en al menos dos sentidos. En uno, porque suponen la negociación de las expectativas y perspectivas de investigación, de formación y de intervención pedagógica de diversos sectores y actores. En otro, porque esos acuerdos respecto de qué documentar incidirán en la formulación preliminar de las coordenadas del trabajo pedagógico entre pares que regularán las prácticas de narrativas y de indagación cualitativa de los docentes durante el trayecto.

Por estos motivos, la determinación de los criterios de identificación y selección puede pensarse como el punto de intersección entre los objetivos más generales de la política pedagógica que ampara a la documentación narrativa y los objetivos más específicos que perseguirán los procesos en territorio. Este esfuerzo por tornar inteligibles y conciliar diversos intereses y sus lenguajes resulta determinante a la hora de convocar a los docentes para que participen en la iniciativa. En el proyecto destinado a documentar mediante relatos de experiencia el mundo de la educación infantil en tres regiones educativas de la Provincia de Buenos Aires que ya mencioné, por ejemplo, la Dirección Provincial de Educación Inicial predefinió su interés por construir relatos de experiencias de "alfabetización inicial" y de "socialización en las normas de convivencia". No obstante, ya en territorio, los procesos locales de documentación narrativa desplegados por las coordinadoras y las docentes narradoras se orientaron hacia otras temáticas que resultaron de su interés. Si bien solo la mitad del corpus de relatos contaba historias pedagógicas sobre las cuestiones preseleccionadas a nivel provincial, las otras narraciones documentadas colaboraron a enriquecer la gama de problemas a incorporar a la agenda político educativa de ese nivel educativo.

Además de ser definitorias en los primeros momentos del itinerario, las tareas de indagación narrativa vinculadas con la identificación y la selección también pueden y suelen estar presentes a lo largo de todo el recorrido. Por un lado, porque el mismo proceso individual y colectivo de interpretación y comentario de las sucesivas versiones de los relatos puede redireccionar la mirada y el interés del docente narrador hacia otras experiencias pedagógicas vividas. Por otro, porque una vez seleccionada la experiencia a documentar, resulta necesario un persistente trabajo de identificación de diversos aspectos de la experiencia (escenarios, contextos, personajes, voces) a configurar en la intriga narrativa del relato. Finalmente, porque se espera que las prácticas de indagación narrativa y autobiográfica de los docentes participantes tienda a reconfigurar y tornar más críticas sus propias modalidades de comprensión y juicio pedagógicos y las formas en que narran los acontecimientos del mundo escolar.

La identificación y la selección implican un conjunto de operaciones intelectuales relativamente complejas. En primera instancia, a través de estrategias de taller, se disponen un conjunto de ejercicios para que los docen- 
tes evoquen experiencias pedagógicas vividas, así como para que releven huellas y rastros materiales de las prácticas pedagógicas desplegadas. Se espera que los docentes puedan indagar en la memoria personal, en la de otros docentes e "informantes clave", en la memoria institucional de la escuela u organización que la albergó, y alcancen a ensayar y bosquejar una primera reconstrucción de la experiencia en cuestión. Posteriormente, se les solicita que cuenten oralmente esa experiencia reconstruida a otros colegas del grupo. El hecho de "contarla a otros" le permite a cada docente participante construir un primer borrador de la trama narrativa del relato $y$, al mismo tiempo, producir una primera objetivación de la experiencia reconstruida. Las preguntas y comentarios de los colegas y del coordinador colaboran asimismo a cuestionar esta primera versión y a provocar la indagación de aspectos poco atendidos, desdibujados o controversiales de la historia.

Luego de estos primeros ensayos, los docentes realizan unas primeras de prácticas de escritura dirigidas a lograr una mayor objetivación de la experiencia, aunque todavía no resulten de ellas relatos de experiencia. La lectura de los pares y del coordinador del proceso de estos primeros textos facilita una nueva ronda de reflexiones e intercambios, que se tornan más fundamentados. Asimismo, esas interpretaciones informan los ulteriores comentarios, interrogantes, observaciones, que se les devuelven al docente que los escribió y que inician una ronda de conversaciones en torno de los bocetos. Como puede apreciarse, las operaciones de investigación narrativa y (auto)biográfica que dispone el dispositivo implican la colaboración reflexiva del colectivo a través de una serie de "técnicas de recolección de datos": notas de campo, entrevistas abiertas, conversaciones con informantes clave, diarios profesionales, fotografías, videos.

\section{Escritura y re-escritura de relatos} de experiencia

El itinerario de la documentación narrativa prevé un segundo momento de trabajo específicamente orientado a la escritura y re-escritura de diferentes y sucesivas versiones de los relatos de experiencia por parte de los docentes, hasta llegar a una "versión publicable" del texto, es decir, hasta que el relato de experiencia en cuestión soporte el conjunto de criterios definidos por el colectivo de pares para la publicación de los textos producidos en el taller. En este momento decisivo los docentes llevan adelante una serie de producciones textuales muy específicas, que tienen como insumos centrales a los relatos orales y los primeros textos producidos en el momento de identificación y selección, pero que también toman en cuenta a los relatos, comentarios y descripciones ofrecidos por entrevistados, otros registros documentales de la experiencia (proyectos y planificaciones, registros de observaciones, reportes de evaluaciones, diarios profesionales, videos, fotos) y, por supuesto, los recuerdos activados, reflexionados y recreados al escribir y re-escribir.

Cada re-escritura es una ocasión para que cada docente profundice la indagación de la experiencia mediante conversaciones y entrevistas en profundidad, trabajo de archivo y sistematización de materiales documentales, nuevos análisis e interpretaciones del material relevado y re-interpretaciones de las situaciones vividas y las acciones realizadas. Cada versión del relato o nuevo relato es una oportunidad para "pasar en limpio" la experiencia, para volver a pensarla, para volver a interrogarla, para volver a nombrarla, pero con otras palabras, sentidos y preguntas. Ésta es la instancia del itinerario en la que se "fija" textualmente, aunque siempre de manera provisoria, a la experiencia, y en la que ésta adquiere un 
grado de objetivación que permite volver a reconstruirla y cuestionarla una y otra vez y con mayor distanciamiento. Al mismo tiempo, es el momento en el que los docentes narradores dotan de densidad pedagógica a la intriga narrativa que articula y da sentido a los distintos sucesos, acciones y contenidos de la experiencia, hasta entonces dispersos y fragmentarios.

A partir de la progresiva configuración de la trama, los docentes narradores incorporan al texto sus propias descripciones e interpretaciones de los hechos narrados, y los tensionan con los puntos de vista de otros participantes de la experiencia. El relato de experiencia va ganando verosimilitud y complejidad a medida que su narrador lo va escribiendo y re-escribiendo a lo largo del proceso de documentación. De manera simultánea, el docente que lo escribe y re-escribe va construyendo mediante su indagación formas de conciencia discursiva de las que no disponía antes. Formación docente, investigación pedagógica del mundo escolar y prácticas narrativas se articulan hasta confundirse en el mismo proceso de documentación.

El recorrido de trabajo sobre las distintas versiones del relato supone, además, el ejercicio de otras prácticas de escritura complementarias, no necesariamente narrativas, que colaboran a tornar aún más reflexivo el proceso y a generar un corpus significativo de documentos y fuentes para cada re-escritura. Además de los relatos de experiencia pedagógica, el momento de la escritura y re-escritura contempla la producción de notas de campo, relatos de experiencias de escritura, estampas, ensayos y notas autobiográficas, índices, esquemas, bocetos, crónicas, cronologías, que acompañan e informan la producción narrativa de los docentes.

Casi todas las estrategias que se despliegan en este momento tienden a convertir el decir y el conversar en escribir y, más precisamente, en escribir relatos de experiencia. Comienzan casi siempre con una provocación para que los docentes destraben la escritura y comiencen a narrar en primera persona. Por las condiciones de producción de textos vigentes en el aparato escolar, las prácticas de escritura de los docentes suelen ser descomprometidas y despersonalizadas, mientras que las reglas de enunciación que propicia la documentación narrativa pretenden que los docentes sean a la vez los protagonistas y los narradores de la historia. Por eso, uno de los primeros ejercicios que se plantea tiene que ver con la escritura de un relato autobiográfico a partir del cual los docentes puedan contar por escrito cosas que usualmente cuentan hablando y conversando. Los ejercicios de taller iniciales están dirigidos a que cada docente defina un "plan de escritura". Las ejercitaciones pretenden orientar una serie de decisiones relativas al título y el contenido del relato, mientras que otras más avanzadas pretenden regular las elaboraciones narrativas relativas a los tiempos en el relato y a la posición del docente como narrador de experiencias pedagógicas que vivió. Al mismo tiempo, otras sugerencias metodológicas del dispositivo promueven la escritura de una cronología y luego de una crónica de la experiencia; y otras, más sistemáticas y complejas, proponen la construcción de un índice y de un boceto o bosquejo del relato de la experiencia en cuestión.

\section{Lectura, comentarios y conversación en torno de relatos de experiencia}

Las prácticas de lectura, comentarios y conversación en torno de los relatos de experiencia que llevan adelante los docentes durante el trayecto de investigación-formación-acción están íntimamente imbricadas con los ritmos, dinámica y lógica de las prácticas de escritu- 
ra de las sucesivas versiones de los textos. No obstante, manifiestan una clara especificidad metodológica y observan una serie de recaudos operativos particulares. En una primera enumeración de las tareas de "edición pedagógica" podemos señalar a las que siguen:

- las lecturas y re-lecturas propias, de otros docentes narradores y del coordinador-investigador del proceso de las versiones parciales y finales de los relatos de experiencia y de otros textos complementarios producidos por los participantes;

- la reflexión, la interrogación y la interpretación, individuales y colectivas, del "mundo del relato", esto es, de los contenidos (aspectos, cuestionamientos e interpretaciones) de la experiencia pedagógica narrada;

- la conversación y deliberación pedagógica entre pares, en un ámbito grupal y regulado por estrategias de taller, en torno de esa experiencias y de los saberes pedagógicos reconstruidos mediante los relatos;

- la elaboración y comunicación a los docentes narradores de preguntas, sugerencias y comentarios escritos y orales, individuales y colectivos, que estén informados en esas lecturas, reflexiones, interpretaciones, conversaciones y deliberaciones sobre los relatos de experiencias en cuestión; $y$

- la evaluación de la comunicabilidad del texto y de la recepción del relato pedagógico, y la toma de decisiones respecto de las oportunidades para su publicación y circulación en circuitos especializados.

Es a través de esta serie de prácticas que los docentes narradores inscriben sus relatos en un circuito de lecturas entre pares, reciben comentarios sobre su texto y entregan comen- tarios sobre los textos de otros, con la finalidad de colaborar en las tareas de la documentación pedagógica y a tornar más densos los relatos que surgen de ellas. Por eso, las actividades desplegadas durante la "edición pedagógica" son decisivas en el proceso de formación e indagación participativa que regula el dispositivo. Pero estas tareas son estratégicas no sólo porque contribuyen a que la producción narrativa de los docentes se torne más voluminosa y se publique, sino porque también están dirigidas a colaborar reflexivamente en el proceso de investigación narrativa y autobiográfica de los docentes protagonistas de las experiencias a documentar, y a ayudar a volver más sutiles e informadas sus interpretaciones y descripciones del mundo escolar.

Este momento del itinerario de trabajo es altamente recursivo y extendido en el tiempo, y a su vez está comprometido con las dimensiones colectivas puestas en juego por el dispositivo. Las actividades de lectura interesada, los comentarios cruzados y la conversación entre pares que se activan durante su desarrollo, convierten los objetos de pensamiento, fijados provisoriamente por la escritura y la re-escritura de los relatos, en objetos de reflexión grupal, de interrogación y cuestionamiento colectivos y de problematización conjunta de las experiencias narradas. La soledad de la escritura y la re-escritura de los relatos se ven así quebradas por la lectura y los comentarios de otros (los pares y el coordinador del proceso), y la intriga pedagógica configurada por el docente narrador en el relato comienza a reconfigurarse en un juego de lecturas y deliberaciones compartidas y de re-escrituras sucesivas, que van constituyendo a esa comunidad de atención mutua en una comunidad de prácticas y discursos pedagógicos especializados.

A continuación presento un fragmento de la reconstrucción de una secuencia de edición pedagógica llevada a cabo en un taller de do- 
cumentación narrativa desarrollado en la localidad de Rosario de la Frontera de la Provincia de Salta, y que está referida al proceso de escritura y re-escritura llevado a cabo por la docente Mariela S. La edición de ese relato se hizo en el marco de un colectivo de docentes de una red de escuelas del Noroeste argentino y estuvo coordinada en territorio por Susana C. con el asesoramiento de un equipo de investigación y coordinación universitario.

Mariela aceptó la invitación a escribir sobre alguna experiencia pedagógica que le hizo Susana $y$, luego de un intercambio personal con ella, su orientación metodológica, varias conversaciones con colegas, la lectura atenta de los materiales pedagógicos que le acercó y la realización de varios ejercicios de escritura preliminares, escribió una primera versión de su escrito:

¡...Y valió la pena!

El salón de actos del Colegio de Jesús en Salta, estaba repleto. Estudiantes, profesores, maestros y padres de toda la provincia se acomodaban como podían en los pasillos y las puertas... ya no había sillas desocupadas. A mi lado, Cecilia Bazán me miró nerviosa, con una sonrisa congelada, quería disimular, ipobre! ¡Las dos temblábamos! Zulma Céliz, la otra autora del proyecto presentado en la XIII Feria de Ciencia y Tecnología estaba ausente, había partido hacia nuestra ciudad de Rosario, con gran pesar, convocada para un trabajo.

“Cómo fue que llegamos hasta acá?", me pregunté... Las imágenes pasaban rápidas por mi cabeza. En Zulma, mi alumna del $2^{\circ}$ año del Profesorado de Física, nació la inquietud que nos llevó a investigar sobre la contaminación del río Rosario, Cecilia se unió al equipo. Queríamos demostrar que nuestro río estaba contaminado con bacterias muy peligrosas... Después, conseguimos un laboratorio en Salta para analizar el agua, vendimos bonos contribución para recaudar cada centavo, nos enterramos hasta el tobillo en el agua y el barro para recolectar las muestras, caminamos con la nariz arrugada en medio del basural, escribimos y discutimos, y volvimos a escribir... Y así llegó la exposición en la escuela Edgar Leal, con el stand armado con mucho esfuerzo y ayuda de familiares y amigos; luego la alegría de "pasar" a la instancia provincial. Las tres agotadoras jornadas en Salta, en las que el jurado preguntó, revisó y evaluó, una y otra vez...

Ahí estábamos: las caras de los estudiantes y docentes eran una mezcla de nervios, ansiedad y hasta angustia. Unos lloraban de emoción, o reían eufóricos, otros lloraban de frustración. ¿Se habrían preguntado ellos, tal como lo hice yo, si valió la pena tanto esfuerzo? Porque en esos momentos pensaba, ¡cuánto trabajo! ¡Cuántas complicaciones! ¿Valió la pena?... Me llegó la respuesta desde el micrófono de la locutora, que ya anunciaba: ..." Y el $1^{\circ}$ premio de la categoría Ciencias Naturales, Nivel $\mathrm{H}$, es para..."

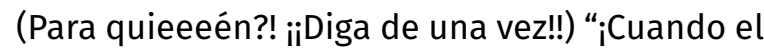
río suena, microorganismos lleva!!... del Instituto de Educación Superior $N^{\circ} 6024$ de Rosario de la Frontera". ¿Qué? Nos miramos con Cecilia, medio sin comprender, no podíamos respirar... Como en sueños caminamos por el pasillo, la ministra Altube nos entregó algo en las manos, la gente nos felicitaba al pasar; "son las del río" decían unos, "son las de Rosario de la Frontera" decían otros... Claro, claro que valió la pena, pensé con lágrimas en los ojos.

Con esta versión del relato, Mariela se integró al taller de documentación narrativa que coordinó Susana y en el que ya venían participando otros docentes narradores. Antes de dar a leer su texto, Mariela escuchó lecturas y leyó versiones preliminares de relatos de experiencia escritos por colegas, escuchó comentarios a esos textos y se animó a pensar ella misma algunas sugerencias, observó cómo los docentes narradores tomaban notas, contestaban interpretaciones, contrastaban puntos de vista, entraban en conversación con colegas a través de sus textos, se recomendaban lecturas pedagógicas para informar la elaboración de los relatos. Después de eso fue animada por Susana a leer su versión 1 del relato. Lo leyó 
en voz alta y recibió varios comentarios orales por parte de la coordinadora y de algunos docentes narradores. Las observaciones de estos docentes estuvieron dirigidas a sugerirle que completara información para poder comprender mejor de que se trataba la experiencia y para redimensionarla. La coordinadora le sugirió que ampliara "un poco más los datos acerca del contenido de la experiencia" y que describiera más el "desánimo" que algunos colegas le provocaron. Frente a esta observación, Mariela manifestó no querer mencionar esto en su texto para "no complicar el escenario institucional contando estas cuestiones". No obstante, durante toda la conversación ella también tomó notas de campo e intercambió puntos de vista, hizo aclaraciones a preguntas y marcó su texto con sus propios comentarios.

Después de eso, algunos de los docentes participantes se llevaron copias del primer relato de Mariela, lo leyeron y le hicieron llegar sus comentarios, preguntas y sugerencias de re-escritura por escrito y con marcas en la versión original. Susana también hizo comentarios de este tipo, y además le facilitó todo este material textual y describió la secuencia de trabajo realizada al equipo de investigadores-coordinadores que no participaba de manera directa en el taller. Luego de analizarlos, este equipo se integró indirectamente en el proceso de edición haciéndole llegar el siguiente comentario a la coordinadora local del proceso:

El relato de Mariela está muy bien contado, las expresiones son graciosas, las descripciones son interesantes.

Nos despertó muchas preguntas y deseos de conocer mucho más de la experiencia que ganó el premio, que del premio mismo.

Y aquí está la cuestión: sería muy bueno que puedan expandir el por qué se decidieron a desarrollar esta experiencia, quiénes y de qué nivel educativos eran estas docentes y estu- diantes, el qué hicieron y el para qué de esta historia. Si no, la experiencia queda oculta o atrapada en el mero hecho de ganar el premio, sin poder ser contada. De una primera lectura se desprende que todo el trabajo "valió la pena" porque recibieron un premio. ¿Y por qué esta experiencia valió pedagógicamente? Esto sería lo rico que falta contar.

Aparece en este relato otra cuestión bien interesante y que se podría trabajar: la autorización de la profesión. Tan necesaria es que a veces oculta los resultados pedagógicos, o quedan opacados por lo otro.

Al respecto, algunas preguntas que podrían ayudar a abrir el texto: ¿Por qué fue tan importante salir premiadas? ¿Por qué ganar un premio hace que una experiencia pedagógica valga la pena?

Como puede apreciarse las observaciones del equipo de coordinación también estaban orientadas a completar información para darle más claridad al relato, pero además avanzaron en sugerir la reflexión individual y colectiva acerca del juego de valoraciones presente en el texto, sobre todo en lo que tiene que ver con el sentido pedagógico de la experiencia para sus protagonistas y narradora y la problematización de las posiciones asumidas. A partir de estos comentarios, Susana siguió animando el proceso de edición y acercándole sugerencias y observaciones sobre su relato a Mariela, quién ya se había dispuesto a la re-escritura a partir de la lectura de los comentarios que les hicieron llegar sus colegas y coordinadora de proceso. De esta manera escribió la segunda versión de su relato de experiencia:

Memorias de una profesora en Feria de Ciencias. Y valió la pena!

El salón de actos del Colegio de Jesús en Salta, estaba repleto. Estudiantes, profesores, maestros y padres de toda la provincia se acomodaban como podían en los pasillos y las puertas... ya no había sillas desocupadas. A mi lado, mi alumna Cecilia Bazán, me miró nerviosa, con 
una sonrisa congelada, quería disimular, ipobre! ¡Las dos temblábamos! Zulma Céliz, la otra autora del proyecto presentado en la XIII Feria de Ciencia y Tecnología estaba ausente, había partido hacia nuestra ciudad de Rosario, con gran pesar, convocada para un trabajo.

“CCómo fue que llegamos hasta acá?", me pregunté... Las imágenes pasaban rápidas por mi cabeza. En Zulma, mi alumna del $2^{\circ}$ año del Profesorado de Física, nació la inquietud que nos llevó a investigar sobre la contaminación del río Rosario, Cecilia se unió al equipo.

Queríamos demostrar que nuestro río estaba contaminado con bacterias muy peligrosas. Nuestro trabajo cumpliría una función social, un servicio a la comunidad; se sabría por qué y en qué medida estaba contaminado el río Rosario, se sabría del peligro que encerraban las actividades recreativas en sus aguas, así como el uso para el riego de huertas. Por mi parte, como docente me había impuesto un desafio: llevar la investigación a la escuela y demostrar que era posible poner el Instituto Terciario al servicio de la comunidad. Así, conseguimos un laboratorio en Salta para analizar el agua, golpeamos muchas puertas solicitando ayuda y a pesar de que pocos se hicieron eco de nuestro pedido, aprendimos que en la vida, cuando se quiere algo con muchas ganas... se puede lograr. No todos nos dieron la espalda y gracias a ellos salimos adelante; vendimos bonos contribución para recaudar cada centavo y poder solventar los gastos del proyecto, nos enterramos hasta el tobillo en el agua y el barro para recolectar las muestras, caminamos con la nariz arrugada en medio del basural, escribimos y discutimos, y volvimos a escribir... Y así llegó la exposición en la escuela Edgar Leal, con el stand armado con mucho esfuerzo y ayuda de familiares y amigos, luego la alegría de "pasar" a la instancia provincial... Las tres agotadoras jornadas en Salta, en las que el jurado preguntó, revisó y evaluó, una y otra vez...

Ahí estábamos, las caras de los estudiantes y docentes eran una mezcla de nervios, ansiedad y hasta angustia, unos lloraban de emoción, o reían eufóricos, otros lloraban de frustración. ¿Se habrían preguntado ellos, tal como lo había hecho yo, si valió la pena tanto esfuerzo? Por- que en esos momentos pensaba, ¡cuánto trabajo! ¡cuántas complicaciones! ¿Valió la pena?... me llegó la respuesta desde el micrófono de la locutora, que ya anunciaba: “... Y el $1^{\circ}$ premio de la categoría Ciencias Naturales, Nivel $\mathrm{H}$, es para..." (¿¿Para quieeeén?! ¡Diga de una vez!) " "Cuando el río suena microorganismos lleva!" del Instituto de Educación Superior $N^{\circ} 6024$ de Rosario de la Frontera!". ¿Qué? Nos miramos con Cecilia medio sin comprender, no podíamos respirar... Como en sueños caminamos por el pasillo, la ministra Altube nos entregó algo en las manos, la gente nos felicitaba al pasar; "son las del río" decían unos, "son las de Rosario de la Frontera" decían otros... Claro, claro que valió la pena, pensé con lágrimas en los ojos. Atrás quedaron las voces de aquellos que desestimaron nuestra labor, de los que nos dijeron que no nos ilusionáramos con la obtención de mención alguna porque en la capital habría cientos de trabajos más novedosos... Mientras regresábamos a nuestro pueblo pensaba en lo que significaba esta experiencia para las alumnas (mis chiquillas); en el incentivo que brindaría a mis colegas, desencantados con esta profesión que a veces es un tanto ingrata (sólo a veces).

En el balance de la experiencia, quedó un saldo positivo que va más allá de un premio. Lo que compartimos y aprendimos científica y humanamente, nos enriqueció como personas, y a mi particularmente como profesional; ahora sé que como experiencia pedagógica, la investigación dentro del aula, hace vivenciar a nuestros alumnos lo que siente un científico cuando se frustra o regocija con su trabajo. Yo recordé por qué elegi ser profesora de biología, y cuánto amo lo que hago: guiar de la mano a "mis chicos" para conocer y valorar juntos la naturaleza. Sí, ya sé que eso de la vocación pasó de moda, pero comprendí que si me tomé tantas molestias en este proyecto, era justamente por esa antigüedad: la vocación por mi tarea docente; y lo bueno, lo mejor de todo es que esto recién empieza!"

En esta nueva versión aparecen remarcadas con negritas las modificaciones y ampliaciones introducidas por la docente narradora. Recuperémoslas de manera muy sintética. En primer lugar, entra al relato un "título concep- 
tual" que enfatiza la propia participación en la experiencia por parte de la docente narradora. Luego, a partir de la inclusión de párrafos enteros, se expande el relato y la narradora aporta información más precisa sobre la experiencia pedagógica en cuestión, que permite conocer los puntos de vista y la puesta en valor pedagógicos de sus protagonistas y vislumbrar los conflictos de poder que provocó localmente e incidian en su autocensura. Asimismo, estos fragmentos textuales añadidos repercuten en la configuración de la trama narrativa del relato y, a través de ello, se modifica el juego de valoraciones puestas en juego por la docente narradora, tornando más denso el relato y más detallada la experiencia narrada.

Veamos ahora, también sumariamente, cuáles fueron las decisiones de escritura de Mariela que apuntó Susana: expandió información sobre la experiencia y multiplicó sus contenidos, censuró por omisión en la expansión del relato, sostuvo la estructura del relato y de los hechos narrados, el tono y el estilo del relato, modificó la estructura argumental de la trama, algunos de los contenidos (asunto, cuestionamientos e interpretaciones) del relato y la valoración pedagógica de la experiencia, al punto que se podría decir que se trata de una experiencia "distinta" de la narrada en la primera versión.

Todos estos elementos, cambios e interpretaciones del proceso de escritura y re-escritura de Mariela fueron puestos en consideración y deliberación del colectivo por parte de la coordinadora del proceso local de documentación. En torno de esa secuencia de edición, Susana elaboró un caso de estudio, reunió materiales y diversos documentos para su análisis y lo presentó al colectivo de docentes narradores del taller. Una de las cuestiones que ocuparon las conversaciones fue el análisis del proceso de indagación y formación desarrollado por la docente narradora y la discusión en torno de las diferentes interpretaciones puestas en juego. Otra fue considerar cómo las sucesivas transformaciones del texto estuvieron apoyadas en decisiones de re-escritura que supusieron a su vez reflexiones individuales y colectivas entre pares. Como complemento de estos ejercicios reflexivos, Susana también sugirió nuevas prácticas de escritura a la docente narradora, pero ahora referidas a la experiencia de indagar y documentar el propio mundo escolar mediante relatos de experiencia pedagógica. El resultado de esas escrituras reflexivas fue un nuevo relato de experiencia de Mariela que se integró a un nuevo circuito de lecturas, comentarios y conversaciones del colectivo. A partir de todos estos materiales e intercambios, el colectivo de docentes y la coordinadora tomaron decisiones respecto de la comunicabilidad del relato y sobre la pertinencia de su disposición pública, y lo remitieron a la coordinación de la red pedagógica para su publicación.

\section{Publicación y circulación de los relatos de experiencia}

Más allá de que se tornen un momento específico hacia el final del trayecto de investigación-formación-acción docente, los problemas políticos, metodológicos y técnicos de la publicación de los relatos de experiencias están presentes a lo largo de todo el itinerario de trabajo. Una vez seleccionadas las experiencias a documentar, durante los procesos de escritura y re-escritura y, sobre todo, en la edición pedagógica, se propician debates e intercambios sobre los "criterios de publicabilidad" de los relatos. Estas instancias colectivas de toma de decisiones se focalizan casi siempre sobre qué relatos de experiencia publicar, y sobre cómo y mediante qué formatos y soportes tornarlos disponibles. De esta forma, las cuestiones relativas a la publicación y la circulación de los 
relatos de experiencias se actualizan a cada paso del trayecto, y convocan a la participación cada vez más activa de los docentes como "editores" de su propia producción narrativa. No obstante, en el transcurrir del dispositivo se distingue con nitidez un momento específico dirigido a debatir y decidir colectivamente las estrategias, soportes y modalidades de publicación. Ya sea a través de ejercicios reflexivos, debates y conversaciones promovidos por la edición pedagógica de los relatos, o mediante la conformación de "comités editoriales" ad hoc, se recorta del conjunto una serie de operaciones que permiten identificarlas como una instancia de trabajo diferenciada. Hacia el final del recorrido, los debates y la toma de decisiones sobre la publicación se vuelven una conversación acerca de cómo intervenir a través de los relatos de experiencia en el debate público y especializado sobre la educación.

La publicación y la circulación de los documentos narrativos constituyen la culminación del proceso regulado por el dispositivo $y$, al mismo tiempo, resulta en un acontecimiento político-pedagógico importante. Toda la movilización y organización de tiempos, espacios y recursos desplegados se condensan en el acto de tornar público uno de sus resultados más concretos. La publicación de historias escolares relatadas por docentes constituye una instancia estratégica del itinerario justamente porque es el momento en que los docentes narradores se convierten en autores de documentos pedagógicos y, a través de ellos, sus saberes y experiencias alcanzan el mayor grado de objetividad y extrañamiento posibles.

El momento de la circulación de los documentos narrativos está articulado con las actividades de publicación y con la tentativa de intervenir en el espacio público y en el debate especializado sobre la educación, a través de relatos de experiencia producidos en redes de colaboración pedagógica. De hecho, la difusión de los relatos de experiencia a través de diferentes medios, soportes y estrategias y en diferentes circuitos de recepción, multiplica el acontecimiento político de la publicación, lo especifica en determinados ámbitos de deliberación pedagógica y lo complementa con su disputa por legitimarse como una forma de saber válida. Sin embargo, las estrategias de intervención a diferentes niveles y con diferentes actores educativos que establece la circulación de los documentos narrativos son de una indole bastante diferente a las anteriores, ya que implican la movilización de esfuerzos, recursos e inventiva de los colectivos de docentes autores hacia otros circuitos de producción de discursos y prácticas pedagógicas.

Por eso, puede describirse como una instancia de trabajo pedagógico entre pares diferenciada que, en términos genéricos, tiende a responder reflexiva, operativa y políticamente a la pregunta sobre qué hacer con los relatos cuando ya están publicados. Su sentido se cifra justamente en promover revisiones efectivas y perdurables en las dinámicas y relaciones de trabajo pedagógico de las escuelas, en las modalidades de organización curricular e investigativa de las instituciones de formación docente y en otros ámbitos del campo educativo en los que el saber pedagógico se crea, se legitima y circula. En última instancia, será la capacidad de los colectivos de docentes narradores de hacer circular su producción intelectual lo que termine validando el dispositivo de trabajo pedagógico entre docentes en el campo pedagógico. Después de todo, esta estrategia de indagación-formación-acción no trata tan sólo de comprender mejor el mundo escolar, sino también aspira a transformarlo a través nuevos discursos y formas de pensamiento pedagógico. 


\section{Referencias}

ANDERSON, Gary L. y KERR, Kathrin. El docente investigador: la investigación-acción como una forma válida de generación de conocimientos. En: SVERDLICK, I. (Comp.). La investigación educativa: una herramienta de conocimiento y acción. Buenos Aires: Noveduc, 2007. p. 47-70.

ARFUCH, Leonor. El espacio biográfico. Dilemas de la subjetividad contemporánea. Buenos Aires: Fondo de Cultura Económica, 2002.

BATALLÁN, Graciela. Docentes de infancia: antropología del trabajo en la escuela primaria. Buenos Aires: Paidós, 2007.

BOLIVAR, Antonio. ¿De nobis ipsis silemus?: epistemología de la investigación biográfico-narrativa en educación. Revista Electrónica de Investigación Educativa, Ensenada, v. 4, n. 1, p. 40-65, 2002. Ciudad de México. Disponible en: <http://www.fts.uner.edu. ar/catedras03/tfoi/2010/Bolivar 2002.pdf>. Acceso el: 13 jun. 2005.

BULLOUGH, Robert. Convertirse en profesor: la persona y la localización social de la formación del profesorado. En: BIDDLE, B.; GOOD, T. L.; GOODSON, I. (Eds.). La enseñanza y los profesores I. La profesión de enseñar. Barcelona: Paidós, 2000. p. 99-16.

CONNELLY, F. M.; CLANDININ, D. J. Relatos de experiencia e investigación narrativa. En: LARROSA, J. et al. (Orgs.). Déjame que te cuente: ensayos sobre narrativa y educación. Barcelona: Laertes, 1995. p. 11-60.

CONTRERAS, José; PÉREZ DE LARA, Nuria. La experiencia y la investigación educativa. En: CONTRERAS; J.; PÉREZ DE LARA, N. (Comp). Investigar la experiencia educativa. Madrid: Morata, 2010. p. 21-86.

SOUZA, Elizeu Clementino de; SERRANO CASTAÑEDA, José Antonio; RAMOS MORALES, Juan Mario. (Coords.). Autobiografía y educación: tradiciones, diálogos y metodologías. Sección Temática. Revista Mexicana de Investigación Educativa (RMIE), MéxiCo, CMIE, n. 62, v. XIX, p. 683-694, jul./sept. 2014.

JAY, Martin. Cantos de experiencia. Variaciones modernas sobre un tema universal. Buenos Aires: Paidós, 2009.
LARROSA, Jorge. Pedagogía profana: estudios sobre lenguaje, subjetividad, formación. Buenos Aires: Ediciones Novedades Educativas, 2000.

MARTÍNEZ BOOM, Alberto; PEÑA RODRÍGUEZ, F. (Comp.). Instancias y estancias de la pedagogia: la pedagogía en movimiento. Bogotá: Universidad San Buenaventura, 2009.

ROCKWELL, Elsie. La experiencia etnográfica: historia y cultura en los procesos educativos. Buenos Aires: Paidós, 2009.

SUÁREZ, Daniel H. La documentación narrativa de experiencias pedagógicas y la democratización del campo educativo en Argentina. En: BRAGANÇA, Inés Ferreira de Souza; ABRAHÃO, Maria Helena M. Barreto; FERREIRA, Marcia Santos. (Orgs.). Perpectivas epistêmico-metodológicas da pesquisa (auto)biográfica. Curitiba: Editora CRV, 2016. p. 99-114.

SUÁREZ, Daniel H. Documentación narrativa e investigación-formación-acción en educación. En: SOUZA, Elizeu Clementino de. (Org.). (Auto)biografias e documentacão narrativa: redes de pesquisa e formação. Salvador: EDUFBA, 2015a. p. 63-86.

SUÁREZ, Daniel H. Pedagogías críticas y experiencias de la praxis en América Latina: redes pedagógicas y colectivos de docentes que investigan sus prácticas. En: SUÁREZ, D. H.; HILLERT, F.; OUVIÑA, H.; RIGAL, L. Pedagogias críticas. Experiencias alternativas en América Latina. Buenos Aires: Novedades Educativas, 2015b. p. 15-54.

SUÁREZ, Daniel H. Espacio (auto)biográfico, investigación educativa y formación docente en Argentina. Un mapa imperfecto de un territorio en expansión. Revista Mexicana de Investigación Educativa, MéxiCo, CMIE, n. 62, v. XIX, p. 763-786. jul./sep. 2014.

SUÁREZ, Daniel H. Récits, autobiographies et formation en Argentine. La documentation narrative des expériences pédagogiques en tant que stratégie de recherché-formation-action pour enseignants. En: GONZALEZ-MONTEAGUDO, J. (Coord.). Les histories de vie en Amérique Latine Hispanophone: entre formation, memoire historique et témoignage. $\mathrm{Pa}$ ris: L'Harmattan, 2014. p. 217-250. 
SUÁREZ, Daniel H. Narrativas, autobiografias y formación en Argentina: investigación, formación y acción entre docentes. En: SOUZA, E. C y SOUZA, I. F. (Org.). Memória, dimensões sócio-históricas e trajetórias de vida. Natal: EDUFRN; Porto Alegre: EDIPUCRS, 2012. p. 57-94. (Pesquisa (Auto)biográfica: temas transversais, 3 ).

SUÁREZ, Daniel H. Docentes, narrativa e investigación educativa. La documentación narrativa de las prácticas docentes y la indagación pedagógica del mundo y las experiencias escolares. En: SVERDLICK,
I. (Comp.). La investigación educativa: una herramienta de conocimiento y acción. Buenos Aires: Noveduc, 2007. p. 71-110.

SUÁREZ, Daniel H.; ARGNANI, Agustina. Nuevas formas de organización colectiva y producción de saber pedagógico: la Red de Formación Docente y Narrativas Pedagógicas. Revista da FAEEBA - Educação e Contemporaneidade, Salvador, v. 20, n. 36, p. 43-56. 2011.

Recebido em: 30.07.2016

Aprovado em: 18.10 .2016

Daniel Hugo Suárez Doctor en Filosofía y Letras (Área: Ciencias de la Educación) por la Universidad de Buenos Aires (UBA). Profesor Titular del Departamento de Ciencias de la Educación de la Facultad de Filosofía y Letras (FFyL) de la UBA. Profesor del Programa de Doctorado y de la Maestría en Educación. Pedagogías críticas y problemáticas socioeducativas (FFyL-UBA). Director del Proyecto de Investigación "La conformación del campo pedagógico. Disputas y sentidos en torno de las desigualdades y diferencias en educación", en el Instituto de Investigaciones en Ciencias de la Educación (FFyL-UBA).E-mail: dhsuarez@filo.uba.ar

Universidade de Buenos Aires, Facultad de Filosofía y Letras

Puán 480, 1420 CABA, Argentina 